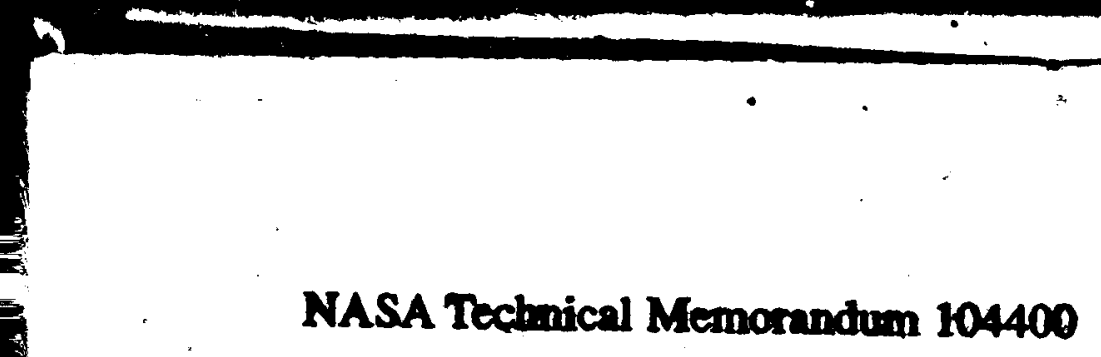

$1 N-39$

14925

p. 9

\title{
Incorporating Finite Element Analysis Into Component Life and Reliability
}

Richard August

Sverdrup Technology, Inc.

Lewis Research Center Group

Brook Park, Ohio

and

Erwin V. Zaretsky

National Aeronautics and Space Administration

Lewis Research Center

Cleveland, Ohio

Prepared for the

Ninth Biennial Conference on Reliability, Stress Analysis, and Failure Prevention sponsored by the American Society of Mechanical Engineers

Miami, Florida, September 22-25, 1991

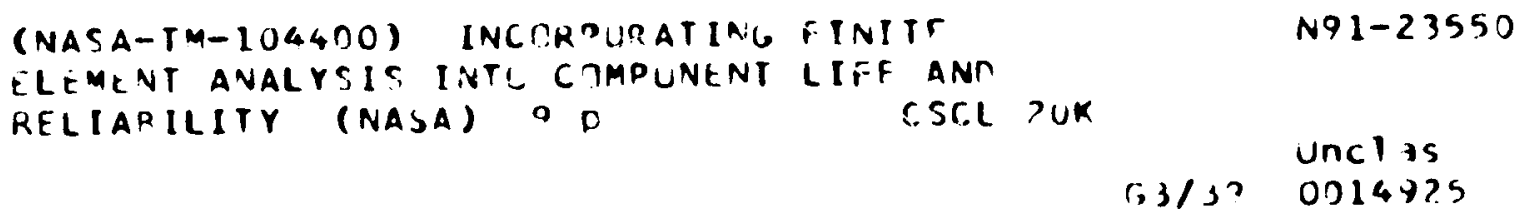

(33/3? 001472.5 


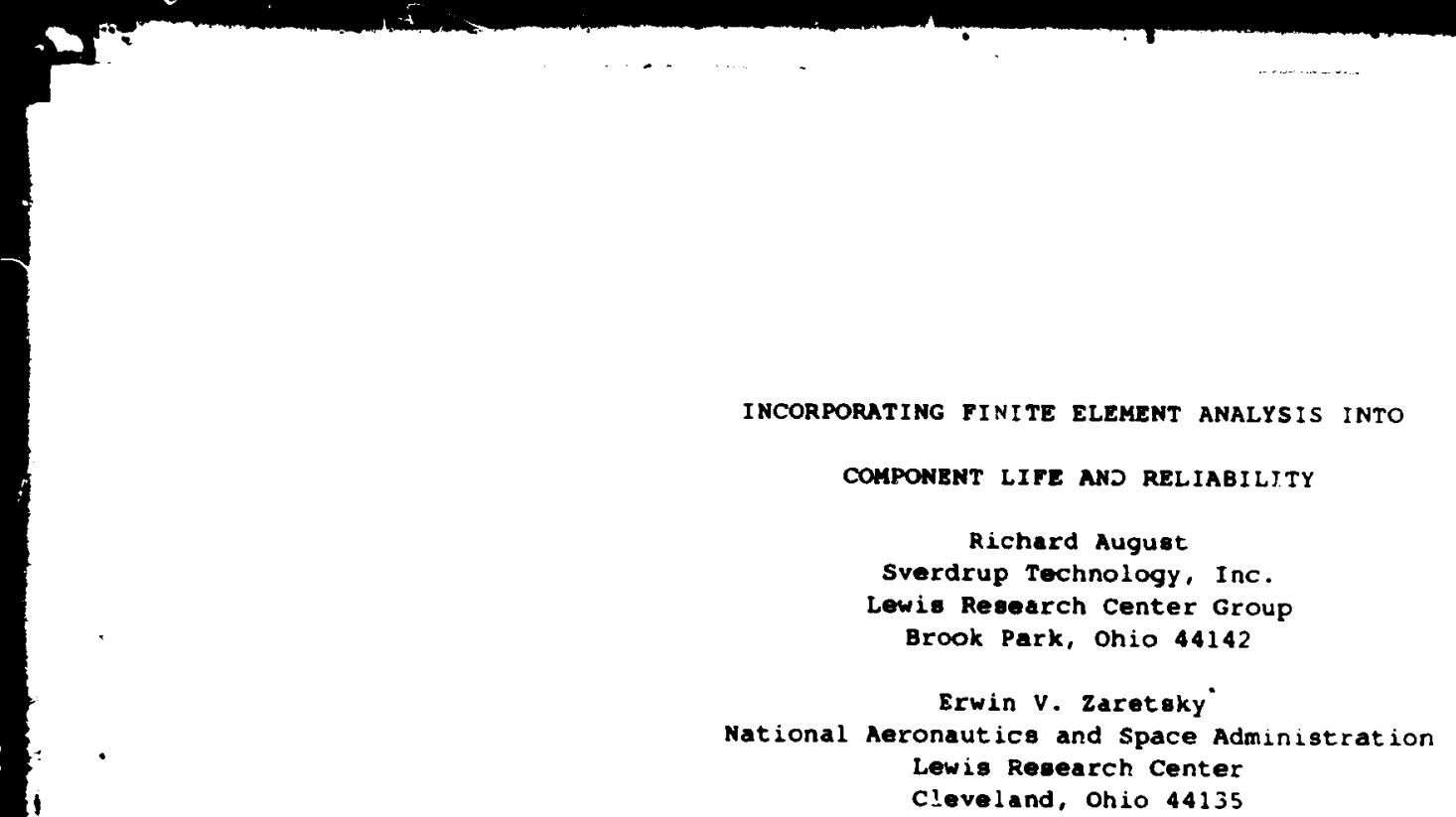

cleveland, Ohio 44135

\section{ABSTRACT}

A method for calculating a component design survivability by incozporating finite element analyais and probabilistic material proper ies was developed. The method evaluates design parameters through direct comparisons of component survivabi:ity expressed in terms of weibull parameters. The ailalyois was applied to a rotating disk with mounting bolt holes. The highest probability of failure occurred at, or near, the maximum shear stress region of the boit holes. Dietribution of material failure ae a function of Welbull sope af focts the probability or survival. Where Weiouid parameters are unknown for a rctating disk, it may be permiseible to asaume weibull parameters, as well as the otress-life exponent, in order to determine the offect of diak speed on the probability of survival.

\section{NONENCLATURE}

c material strese-ilfe exponent

- Weibull elope of materlal modulue

L wrese cycles to fallure

$L_{1}$ atrees cycles to failure of $1^{\text {th }}$ component

$L_{0} \quad$ atrese cycles where 37.7 percent of apecimens ourvive

L. etrees cycles to fallure of total eyetem

$L_{u} \quad$ strese cycles where all epecimene eurvive

$S$ otatiat Lcal fraction of opecimene that aurvive a given number of atreas cyclee

\author{
s. total eystem survivability \\ v atreased volume \\ $\tau$ ocreas level applicable for failure theory
}

Subscripts :

$a, b$ states a and $b$, or bodies $A$ and $b$

INTRODUCTION

A key component in any structural design process is establishing a minimum acceptable service life and then determining the potential of component or etructural failure before that minimum life ie achieved. A though components may be tested to faijure t? determine their functional life, this method is certainly impractical in terms of time requirement: s, the tifficulty in imulating all possible loading conditions, and the expense involved in full-scale testing. Also, early-atage designs generally undergo fuite a few iterations until a final set of specifico:ions is formalized.

Many applications, especially in the aerospace induetry, include ize and weight constrainte. This precludes utillzing life-enhancing design features, wuch a ultraconservative safety factore, or using etronger, but heavier, materials. In order to realize the lightest, mcst compact design, components are purposely designed for finite life (i.e., expected failure), with very high probability of survival throughout the entire duty cycle. The mot efficient oyotem optration then involves regularly scheduled component replacement, so that the prede'ermined time between replacements -8 only olightly shorter than the anticipated life of the component.

often, empirical-based design techniques are employed for fatigue-tolerant designs. Although such procedures may result in su-cessful designs with respect to fatigue considerations, the designg will probably not be effictent with respect to gize or

Fellow, ASME. 
cost. Also, the ure of now materiale without en experience data bace will pose a problem in making deeign decisione. For these reasone analytical-besed life design methodologies are required to predict component life and curvivability without the need for extensive teating or field experience.

First-order life prediction methode are generally based simply on yield and fatigue-limiting etresees. often, they do not account for geometry and ize effects, surface condition, duty cyclea, and environmental factors. The material life data are also frequently misinterpreted. Stress-life curves are often assumed to be completely deterministic when in fact the strest-life data are presented ac statiotically averaged values. Finally, most life analyses are primarily concerned with a few critical areas in the component (i.e., the areas of highest stress). However, for designs with low stress gradients areas of probable failure are not intuitively obvicus.

Finite-life component design requires a probabiIstic approach that couples operating life with an experced rate of survival. We bull (1939) demonstrated a statisticel analysib that was parcicularly effective in describing experimental fatigue data. Lundberg and Palmgren (1947) applied Weibull analyEis to contact-stress, high-cycle-fatigue bearing problems. Gribaffe (1965) demonstrated the applicability of a weivull-based analysis to other types of durability problems. Ioannides and Harris (1985) and zacetsky (1987) proposed a generalized Weibull-based methodology for structural fatigue iffe prediction based on a discrete-stressed-volume approach.

zaretsky et al. (2989) coupled this methodology to a stress field determined by finite element methods to predict the life and reliability of a generic, rotating disk. They also demongtrated the applicability of the methodology to the design process through parametric studies that showed component iffe bensitivitles to such design variables as disk diameter and ihickncos and bolt hole slze, number, and location. Nemeth et al. $(2990)$ developed a computer program for quant:fying reliability that is based on inherent flaws found in ceramics. Tue program calculates the fast fracture reliability of macroscopically $180 t r o p i c$ cer allac components. This method is also based on the component s entire stress state, not just the maximum stress point.

Although these methods allow the determination of a total component $12 \mathrm{fe}$, it is often necessary to exanine ciltical areas of the cumponent in order to predic: the probability of local failure. In thas manner designs could porentialiy be optimized away from known crilisai areas through appropriate sizlng. Therefore. the oljectives of this investigation are (1) to extend the method of zaretsky (1987) to allow for calculating the local probability of fallure within any compcnent's stressed volume as well as wishin the ent 1 rs component and (2) to demonetrate the technique on a generic disk by examining the sensitivity of stressedvolume survivability to uncertainties in the material properties.

\section{ANALYTICAL METHODOLOGY}

\section{Statistical Fallure Theory}

Experimental fatigue data can often be plotted as atraight ine on weibull probability paper. For a conctant otrese level the number of iress cycles to fallure (i.e., life) is plotted on the abeciesa. The percentile of opecimens that urvive at a given life 18 picted on the ordinate. The trancformation of atreas cycles and eurvivability into weibull coordinatea i given by the equation

$$
\ln \ln \frac{1}{s}=\ln \left(L-L_{u}\right)-\ln L_{0}
$$

where $S$ is statistical fraction of specimens that survive a given number of etress cycles, $\theta$ is the Weibull slope, $L$ is etress cycles to failure, $L$ is otress cycles where all specimene survive, and is stres cycles where 37.7 percent of specimens survive. This is refersed to as a three-parameter Weibull equation. A two-parameter Weibull equation in obtained by setting $L_{,}=0$. The Weibull slope provides an indication of "the scatter of the statistical properties, with $e=1,2$, or 3.57 being representatrve of exponential, Rayleigh, and Guassian distributons, respectively.

The number of stress cycles to failure at a given stress level can be related to stress cycles to failure at a new stress level by the equasion

$$
L_{D}=L_{B}\left(\frac{\tau_{D}}{\tau_{D}}\right)
$$

where $L$, is the knowr. Iife at stress level $\tau$, and $c$ is the stress-life exponent obtained from coupon testing. Weibull (1939, 1951) expressed the $F$ jbability of survival as

$$
\ln \frac{?}{s}-\tau^{\prime} L V
$$

where $l$ is the stressed component volume. $B_{\ddot{j}}$ Lisirig Eq. (3), the siz effects on survivatility for equali: stressed volumes can be expressed as

$$
s_{r}=s^{\prime}
$$

After component iffe and survivability have teer adjustcd on the basis of stress ievels and stressec volume, all other combinations of life anc survivali:lty can be calculated. This allows valid comparisor. of relative component life at equal survivability : relat ive component survivability at equal il :e

Using Eqs. (1) to (3), zaretsky (1987) devei-per ar expression for predicting 11 fe at a glver. surva bllity of a ctressed component $b$ relative to the known il te of a stressed component a :

$$
L_{r}=L_{0}\left(\frac{\tau_{0}}{\tau_{1}}\right)\left(\frac{v_{n}}{v_{t}}\right)
$$

This equation gives the component's ilfe reiative allother samlar component when both have the same survivabilit $y$. The gystem lafe can then he raicijaces from the individual component ives as icliows:

$$
\left(\frac{1}{L}\right)^{*}-\sum_{i=}^{\infty}\left(\frac{1}{L}\right)^{*}
$$

where $i$, 1 s the tutal syotem te sni $i$ a the : component life (2aretsky, 1987). Zaretsky methid can be extended further to examine relat ve component ourvivability at equal lite. Trite in given $p$

$$
\text { s. }=5
$$


Equation (7) can be used to identify critical fatigue componente within a yetem and to optimize noncritical ones. Because a minimum life is required of all componente in the yetem, individual component arvivability at that iin can be aeseesed relative to a predetermined criticial component. In thie manner, components whose survivability is judged to be too low can be redenigned for greater survivability. Aleo, component: whose survivability is much greater than that of the critical component can be redeaigned for amaller ize or lower weight while still maintaining adequate protection against failure.

Finally, the component survi ability is equal to the product of all the elements. survivabilities:

$$
s_{1}=\prod_{2=1}^{n} s_{1}
$$

\section{Incorporating Finite Element Analygis}

The methodology just described can easily be incorporated into the finite element method to determine the life and survivability of a structural component. The entire component is analogous to a system. The finite lement model of the component discretizes its geometry into elemental volumes. These elements are considered to be the base members of the "system." The time to crack initiation for each element is calculatid from the elemental stress levels and volume as descr bed previously to determine the component's incifient failure time. Elemental survivability is also calculated to find areas that have either too low survivability or are overdesigned.

A relative comparison approach is used in this methodology. A critical element $i .$. iti: model is selected on the basis of a maximum stress state. The selected stress failure criterion can be based on the materzal used in the component. If no fatigue data are available, the stressed element can be arbitrarily assigned a life and a survivability that is used to normalize the life and survivability of the other elements. This approach allows easy, qualitative comparlsons between designs. Also, only one set of coupon fat ique test at operating temperatures is necessary to $f: x$ the weibull parameters and to establish quantitative component lives if the stress-life exponent of the material is already known. However, if the stress-life exponent is not known, at least two additional sets of coupon fatigue tests will be necessary

A methodology for predicting elemental survivability at a fixed life is illustrated in Fig. 1. The critical element's life and survivability is set at unity and 90 percent, respectiveiy (point 1). This 18 the analysis point to which all the other elemencs. lives and survivability will be referenced. Other design can also be referenced to this point by uring the same critical volume and strese. The expected survivability at any number of atrees cycles can be determined by using Eq. (1). Thls is shown in the figure by drawing a ine through the reference point with a slope equal to $\theta$, the material' Beibull slope.

Next, an element survavability is adjugted based strictly on yolume effect by ueing Eq. (4) (point 2). Th2s adjustment i done independently of the stress levels. Because tress is not involved. elemental if if not affectad, and the adjugtinent resulte in purely vertical dieplacement from the reference point. In the example shcwn, the second element volume ia greater than the critical volume and contains more potential crack inltiation ites. Therefore, the adjusted urviobility is lower.
The element'. life is then edjusted etrictly on the basis of elementel etrees relative to the critical otreas by using Eq. (2) (point 3). This adjustment is done independently of volume coneiderations. Consequently, elemental eurvivabllity is not ef fected, and the life adjustment results in purely horizontal displacoment at constant ourvivability. In the example shown, the second element's stress is lower than the critical stress. Therefore, it life is greater and shift. to the right.

A new material weibull lir.e is now drawn through the adjusted life/survivability point. Because the compared element's material is the same as the critical element's material, the line is drawn parallel to the original line. However, if the elements had disoimilar materials, the new line would be drawn with the new Weibull slope. Thus, designe incorporating different materials can be compared with respect to aurvivability.

By using Eq. (7), the compared elenent's survivability is adjusted once more to the critical ele. ment assigned life of unity (point 4). This +j.ne the displacement is along the Weibull $l$ ine and gives the survivability of an element relative te the critical element, with both elements having the ame life. Repeating this procedure for all the elemenis in the finite element model gives the sur: ivabilicy for any section of the design at any time.

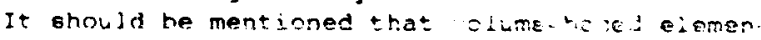
tal survivability will be somewhat in luenced su the finite element mesh, especially with component that experience fairly uniform stress. For this case volumetric ratios will have more effect on lemental survivability. For components with nonuniform stress distributions, exponential stress 12 ice will have more influence on elemental sur"ivability. For thie case the methodology complements traditional finite element modeling philosophy. in that high-stres:gradient areas should be modeled with smaller elements. In this way sizing effects ande minized. in both cases an adaptive meshing techniyle could be used to explicit? y optimize the finite element model sizing and to implicitly minimize the mesh size effects on elemental survivability. From Eqs. (4) and (8) te can be shown that component aurvivability remains inaffected by the individual element mesh.

\section{RESULTS AND DISCUSSION}

Parametric analytical studies were conducted to calculate speed effecta on the survivability of a generic disk and to examine the probabilistic effects of material properties on disk survivability. The generic disk represents the iisat tep in the invest:gation of aerospace propulsion turtine disks. It is $61 \mathrm{~cm}(24 \mathrm{ln}$.$) in diameter and has i welve 1.02-\mathrm{cm}$ (0.40-in.) diameter bolt holes.

Figure 2 (a) shows the finite elemint model of the disk used in these studies. From the axisymeiric conditions of th disk a 15 degree sectior of the disk 18 modeled with 02 gxid pounts and 42 esght.noded solid elements. Boundary conditzons, definea in :erms of the model's cylindracal coordinates, constra. il displacement in the circumferential direction and al ow displacement in the radial and axial directions. The disk stresses are a result of the centrifugal load due to diek rotation. No thermal loads were included. mSC/Nastran was used for the finite element code. The linear elast ac analyos option, SOL 24, was uged to calculate the seresess. Although this anajysis is limited to atrese level below the yield point, it can be used for high cycle fatague where ctresses are 
lower and the occurrence of fallure 1s lees deterministic and more probabilietic. However, because the etatietical fallure thoory is baeed on strene level. and dietribution, the life and rellability methodology can also be adapted for nonlinear enalyaus.

Table I llete the assumed lsotrople materlal properties used in the analyaes. The probabilistic espect of the material etrength is given in the $L$ 1ife of the materiel. This $L_{10}$ life represente the life In the number of strese cycles in which 90 percent of the tested coupone survive at a conatent maximum thear etrese. By ueing the values of Table I, a finite element etrese analyois was performed on the yeneric disk of Fig. 2 (a) at a spoed of $12800 \mathrm{rpm}$. Figure 2 (b) howe the reeulte of the etress analysis. The maximum shear strees was approximately $275800 \mathrm{kN} / \mathrm{m}^{2}(40 \mathrm{ksi}$ ) at the bolt hole. The failure probability analysis for each of the model's element. was then calculated by ueing Eq. (7). The remults shown in Fig. $2(c)$ indicate that the region with the lowest reliability (i.e., the highest probability of failure) occurred at, or near, the maximum ohear stress region at the bolt hole. However, outuide this region the disk had relatively high regione of survivability.

Figure 3 graphically ohowe the relation between life and urvivability for the material in rable I at an asoumed Weibull slope. For a Welbull lope of $3.57,99$ percent of the samples survived 6000 cycles. 90 percent survived 10200 cycles, and 10 percent survived 20000 cycies. A righer value of weibull slope would demonstrate iese scater, with failures occurring over amaller tumber of strese cycles. A lower value would show failurse over a broader range of lives and therefore might be indicative of more uncertainty in the material lives.

Figure 4 hows the effect of a disk's rotational speed on its probability of achieving a life of 10000 stzess cycles. The speed effect was plotted for an assumed Weibull slope of 3.57 and atress-life expo nent of 9. The disk first experienced a maximum shear stress of $275800 \mathrm{kN} / \mathrm{m}^{2}(40 \mathrm{kmi})$ at apeed of $\$ 2800 \mathrm{rpm}$. This disk had a probability of survival of about 96 percent at this peed, which was higher than the coupon urvival rate of 90 percent at the same stress and number of cycles.

The higher probability of survival was due to the volumetric effects. The $275800-\mathrm{kN} / \mathrm{m}^{2}(40-\mathrm{ksi})$ trese region in the disk was much omaller than the gage volume of the coupon. The location of the maximum trese in the model occurred at the lement adjacent to the bolt hoie, at the three o'clock poultion. Also, the Btrusea in the romainder of the dink elemente were much lower than $275800 \mathrm{kN} / \mathrm{m}^{2}(40 \mathrm{kgi})$ and had individually high survivability. Therefore, they had hardly any effect on degrading the diak survivablity. As a result, the diok showed a probability of survival greater that the coupon $L$ life.

The individual calculated elemental survivabilities can also be examined for design optimization. Regione with low-eurvivability element can be redesagned to increase reliability. Simplarly, regions containing elemente with unnecessarily high survivability can be optimized through redesign to reduce weight.

rigure 5 showe the effect of epeed on the cumuletive probability of fallure (i.e., 1 minus the eurvivabilityl with varying waibull elopes. Thie figure demonet ratee how the dietribution of fellure. function of weibul: lope effocte the probability of eurvival. All three curves intermect at 12800 rom, with a 4 percent tailure 196 percent eurvivell, becauce the $L_{10}$ life reference etrees of $275800 \mathrm{kN} / \mathrm{m}^{2}(40 \mathrm{kgl})$ firiot happena et $12800 \mathrm{rpm}$.
Above this opeed the rate of fellure was definitely higher with higher Weibull elope. The 50 percent fellure probabllity occurred at 13100 rpm for a Weibull elope of 2, at $13300 \mathrm{rpm}$ for a Woibull elope of 3.57, and at $24000 \mathrm{rpm}$ for a wolbull slope of $\mathrm{s}$. below 12800 rpw the value of the Weibull elope had little effect on ourvival probablitty.

often, materiel late will be incomplete, if available at all, and tesigners muet use engineering judgmont in eotimat!ng waterial uncertaintios. Where weibull parametere are unknown for a rotating diek, it may be permi asible to ascurse the Weibull elope and the -trese-1ife exponent, in order to determine the diek opeed at which the probability of curvival will bo high. From Fig. 5, the eavimate of the weibull alope should be high for conservative design by anticipating a higher failure rate than would probably occur.

Figure 6 showe the effest of epeed on the cumulative probability of failure with varying etreas-life exponente. There is not the degree of divergence of the three curves above $12800 \mathrm{rpm}$ as there was with Weibull elope variations. The same generel trends huld, higher failure rates witi higher etrese-life exponent, but not to the same extent as in Fig. 5. At high ourvivability values, the value of the tresslife exponent har: little effect at any given speed.

\section{CONCLUDING REMARKS}

Probabilistic material properties expressed in terms of Weibull parametere were coupled with the -tress field determined from MSC/NASTRAN Einite - lement analyeis to determine satigue 11fe baeed on crack initiation. Thil methodology can bo epplied to predict the probability of survival of the complete structural component as well as to identify critical failure regions of the component. A unique advantage of this approach is that only coupon fatigue testing is needed to establish the material fatigue parameter. necessary for full-size componert life and survivability analyais. Thus, this technsque can be used in the carly design stages to optimize life-based designs. thereby reducing the amount of suld-size component testing required to validate these designs.

\section{SUMMARY OF RESULTS}

A method for calculating a comporent' design ourvivability that incorporater finite element analy-is and probabilietic macerial properties was developed. The method evalustes des ign parameter through direct comparison of component survivability expreseed in terms of weibull parameters. The method considers the component' total strese stale in the survivability calculation. Critical regione with respect :0 -urvivability can be identified for optimization purposes: Reliability can be improved at lowsurvivability regiona; and wight can be reduced in high-arvivability rogion. The analyeis was appiled to a rotatiny diek with mounting bolt holes. The following resulte were obtained:

(1) The highest probability of fallure for the disk occurred at, or near, the maximum shear strese region at the bolt hole.

(2) Dietribution of failure a. a function of weibull slope affected the probeblitity of survival. ror opeede that irduced etreeses above the $L$ life reference etrees, higher Weibull olope predicted lower ourvival probability. However, the value of the welbull -lope had iltele effect at eny given epeed at high probebllitles of curvival. 
(3) The etrese-11fe exponent affected the reliablilty predictione. For apeede that indueed etresees above the $L_{10}$ life reterence etrese, higher otree-1ife expcnente prodicted lower curvivel probability. However, the vaiue of the etrees-life exponent had little effect at any given epced at high probabilities of eurvival.

(4) Where Weibull parametere are unknown for a rotating diek, it may be permiesible to aseume Weibull perameter as well a the etrees-life exponent in order to determine the diek upeed at which the probability of eurvival will be highest.

\section{REFERENCES}

Grieaffe, S.L. " 1965, "Analysis of shear Bond strength of Plaema-sprayed Alumina coatinge on stainlese steele," NASA TN D-3113.

loannides, $\boldsymbol{E}$.. and Harris, T.A., 1985, "A New Fatigue Life Model for Rolling Bearinge," Journal c.f

Tribology, Vol. 107, No. 3, pp. 367-378.
Lundberg, G. and Palogren, A., 1947, "Dynanic Capacity of Rolling Bearing," Ingenlore Vetanekepe AkedemienHendlinger, No. 196.

Neanth, M.N., Menderoheid, J.H., and Gyekenyeni, J.P. 1990, Designing Ceranic Componente With the CAREs Computar Program," American Ceramic society Bulletin, vol. 68, No. 12, pp. 2064-2072.

Weibull, W., 1939, "The Phenomenon of Rupture in Solids." Ingerilore Vetanskape Akadamien-Handlingar, No. 253.

Weibull, Ww, 1951, "A statiotical Dietribution Function of Wide Applicability," Journal of Applied Mechanice, Vol. 18, No. 3, PP. 293-297.

zaretsky, E.v., 1987, Fatigue Criterion to syetem Design, Iife and Reliability," Journal of Propuleion and Power, Vol. 3, Nc. 1, Pp. 76-83.

zaretsky, E.V., Smith, T.E., and Auguet, R., 1989, "Effect of Design Variables, Temperarure iradiente, and speed on Life and Reliability of a Rotating Diok," Journal of Vibration, Acoustice strese, and Reliability in Deeign, Val. 111, No. 3, PP. 311-317.

TABLE I. - ASSUMED ISOTROPIC MATERIAL PROPERTIES

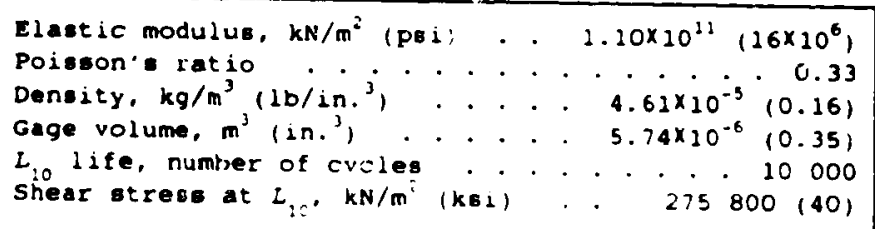

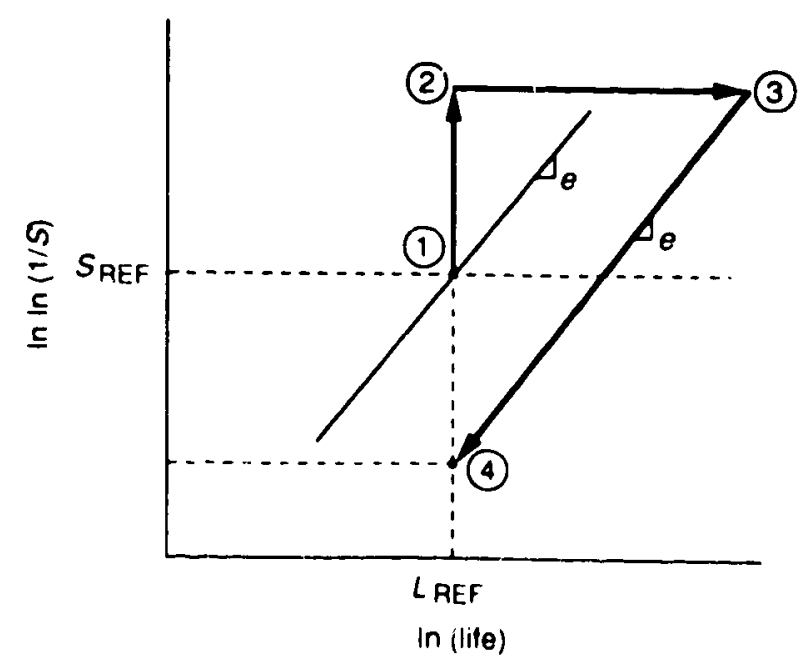

Figure 1. Elemen! s'svivability methodology 


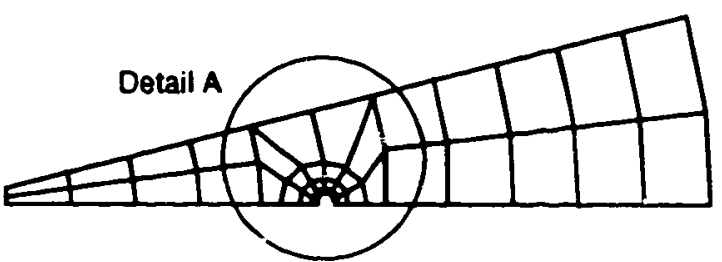

(a) Disk finite element model.

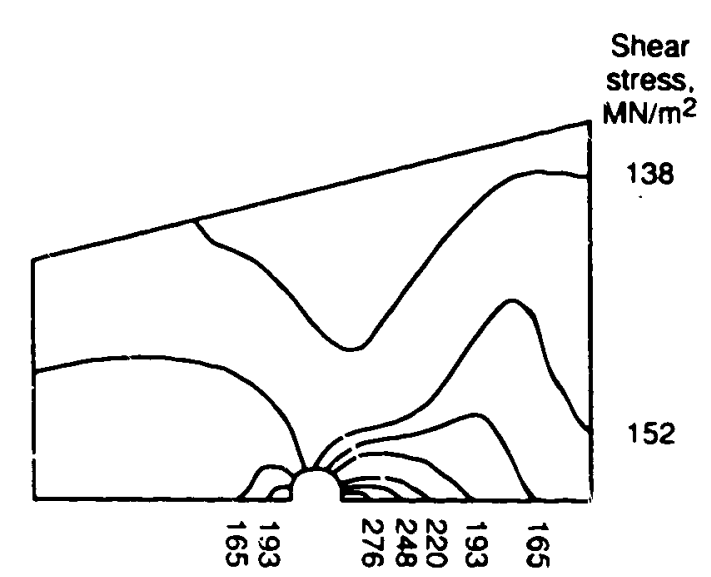

(b) Shear stress contours at detail A

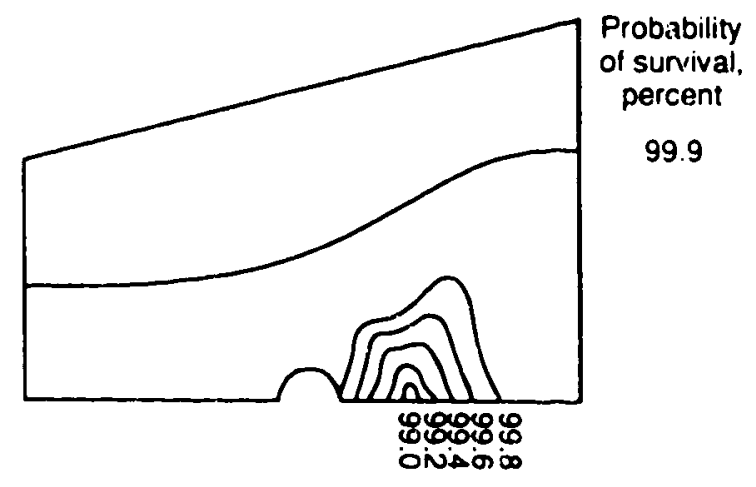

(c) Probability of survival con!ours at detail A.

Figure 2.-Disk linite element model and analysis results. Nominal disk configuration: disk diameter. $0061 \cdot \mathrm{m}$ (24-in.); disk speed, $12800 \mathrm{rpm}$; welve $1.02-\mathrm{cm}(0.40$-in.) diameter bolt holes located on $0.030-\mathrm{m}(12$-in.) diameter.

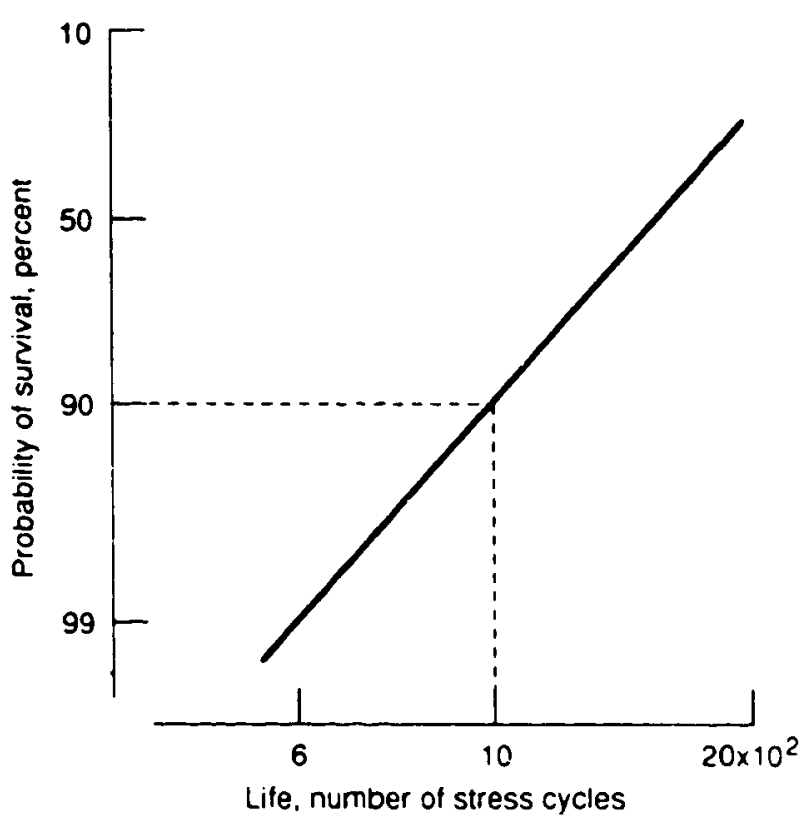

Figure 3.-Assumed material survivability at $275800 \mathrm{kN} / \mathrm{m}^{2}$ (40 ksi). Weibull slope. 3.57.

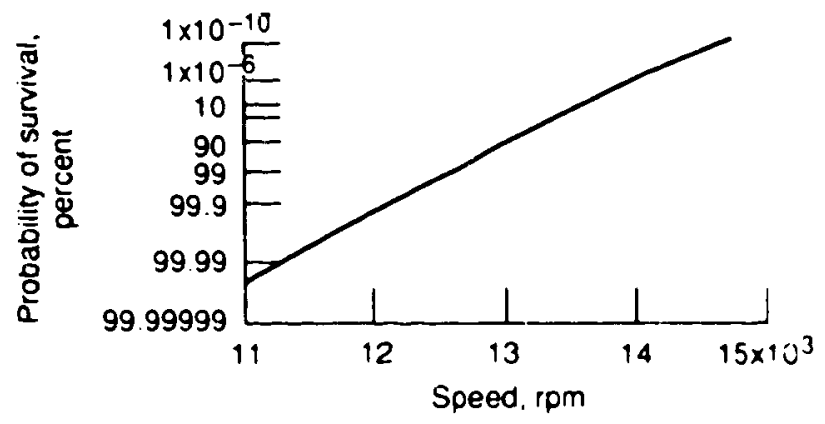

Figure 4.-Effecl of speed on surviv. ability at 10000 cycles Stress life exponent, 9; Weibull slope, 3.57 


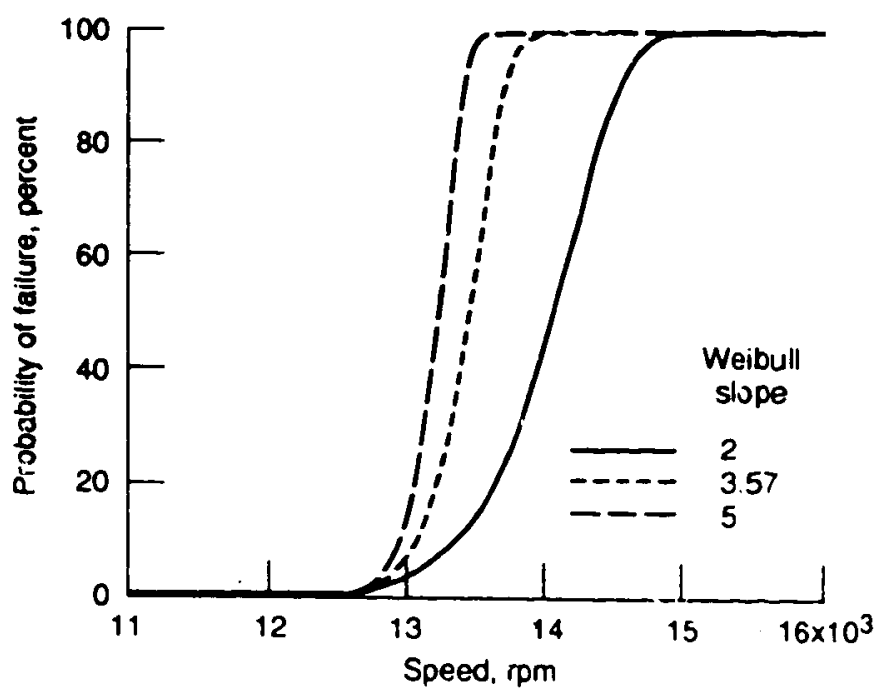

Figure 5.-Effect of Weibull slope on survivabiiity at 10000 cycles. Stress-life exponent. 9.

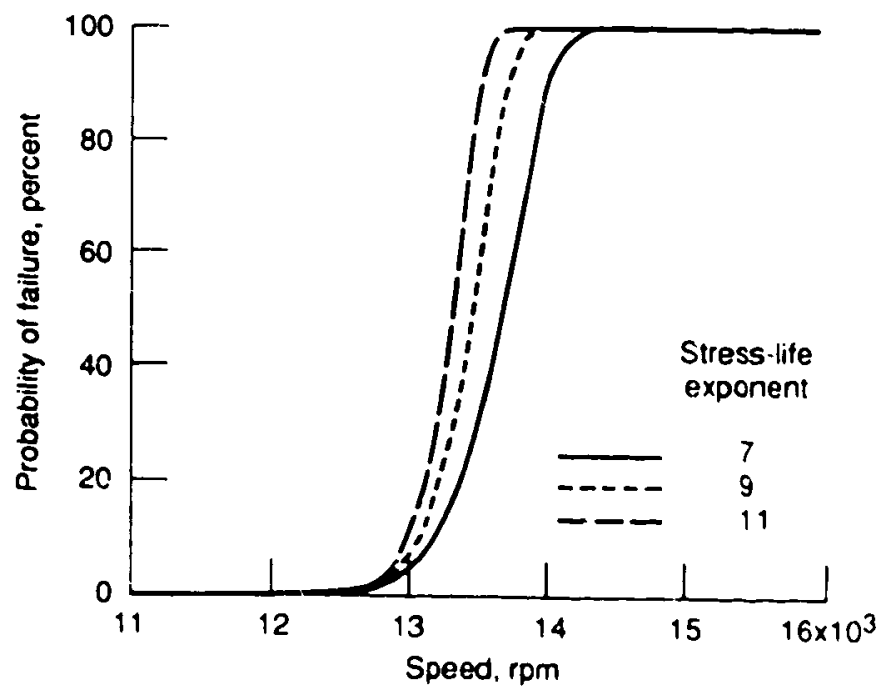

Figure 6.-EHect of stress-life exponent on surviv ability at 10000 cycles. Weibull slope. 3.5? 


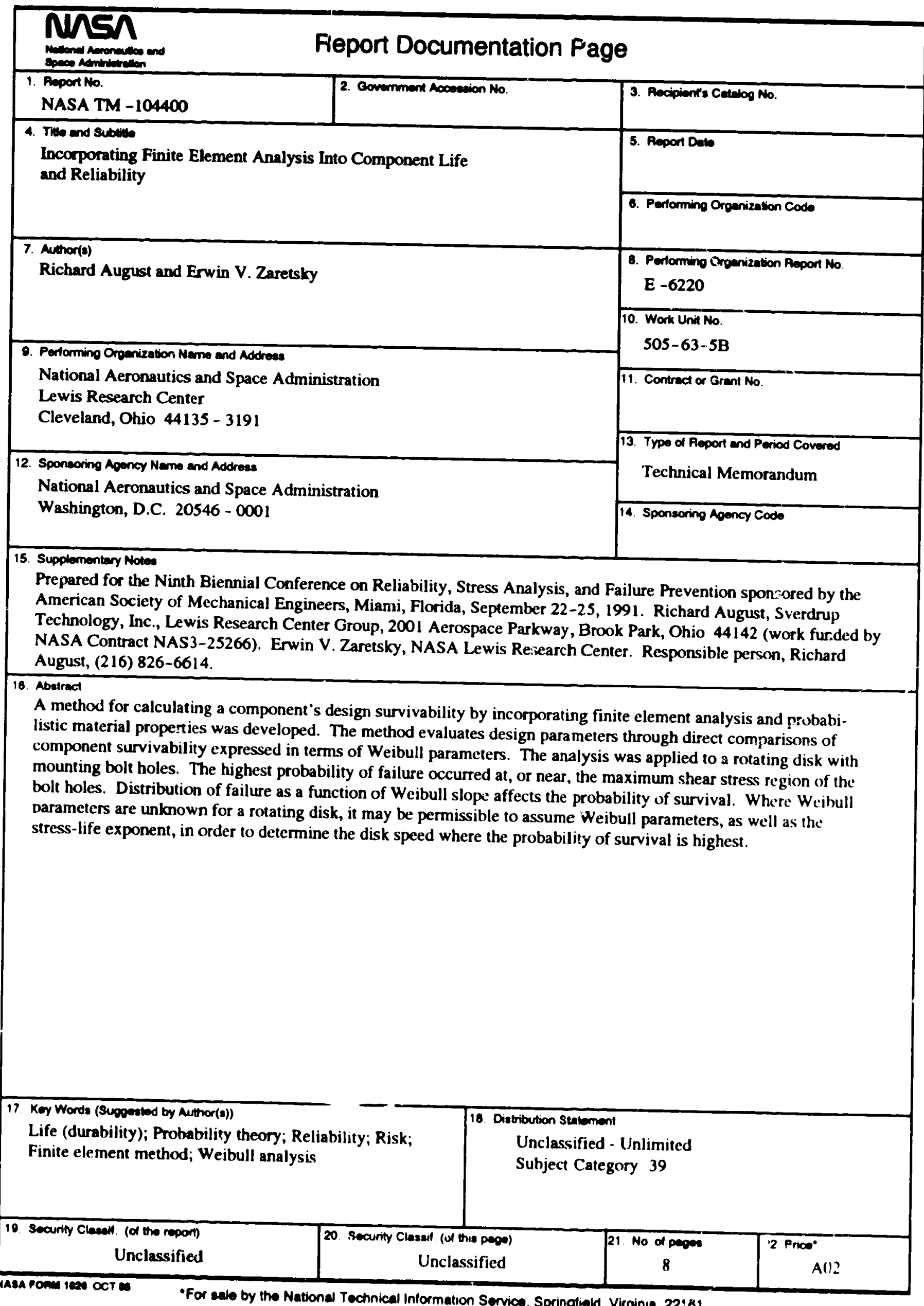




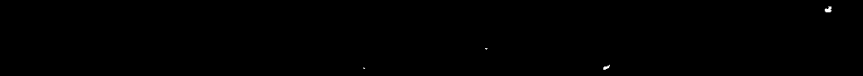

